\title{
PENGARUH EMPLOYEE ENGAGEMENT DAN WORK LIFE BALANCE TERHADAP TURN OVER INTENTION DI GENERASI MILLENIAL
}

\author{
Lita Chrisdiana \\ Program Studi Magister Manajemen Universitas Tarumanagara \\ litachrisdiana@gmail.com \\ Mukti Rahardjo \\ Program Studi Magister Manajemen Universitas Tarumanagara
}

Masuk : 14-11-2017, revisi : 07-12-2017 diterima untuk diterbitkan : 07-12-2017

\begin{abstract}
The purpose of this study was to analyze influence of employee engagement (X1) and work life balance (X2) on turn over intention (Y) in millenial generation DKI Jakarta. This research used non-experimental quantitative design, with nonprobability and snowball sampling technique. Subject of this study consisted of thirty-one respondent who were work in Jakarta area, age between 20 until 36 years old. Data analysis is using multiple linear analysis with additional supported application of SPSS ver.23. result obtained from the data analysis showed with significance level 0,05 , employee engagement ( $t$-count $=-1,162)$, which means Ho is accepted, which indicates there is a negative relationship between employee engagement and turn over intention. Moreover, work life balance ( $\mathrm{t}$-count $=+2,534)$, which means Ho is rejected, which indicates there is a relationship between variable work life balance and turn over intention.
\end{abstract}

Keywords: Employee Engagement, Work Life Balance, Turn Over Intention

\section{PENDAHULUAN}

Sumber daya manusia merupakan aspek yang berperan penting dalam perkembangan manajemen sebuah perusahaan. Di era globalisasi ini, pengklasifikasian kriteria dan pengelolaan sumber daya manusia pun semakin beragam. Pengklasifikasian kriteria ini juga terjadi di dalam lingkungan bisnis Indonesia. Hal ini didukung oleh riset yang dilakukan oleh Dale Carneige Training Indonesia, dihasilkan bahwa generasi Y atau millenial adalah generasi yang akan selalu berkembang di Indonesia dan menjadi populasi pekerja terbesar saat ini. Generasi millenial ini dihadapkan pada generasi lainnya, seperti Baby Boomers dan generasi $\mathrm{X}$. Adanya beberapa jenjang generasi yang tersedia di dalam perusahaan dapat memungkinkan timbulnya konflik antar generasi yang akan berdampak pada turnover karyawan (Eaton, 2008; dalam (Prameswari \& Respati, 2014). Penttila (Hillman, 2014) mengatakan bahwa konflik yang tidak diselesaikan akan membuat karyawan tidak puas dan menimbulkan tingkat turnover tinggi, serta rendahnya produktivitas dan profit.

Badan Pusat Statistik Indonesia (Suhaimi, 2016), di tahun 2016 generasi Y atau millenial mengalami kenaikan hingga $40 \%$, generasi X $15 \%$ dan baby boomer $5 \%$. Berdasarkan data Jumlah Penduduk DKI Jakarta menurut kelompok umur tahun 2015, dihasilkan bahwa 2.977.696 penduduk merupakan generasi millenial dan 2.666.947 penduduk generasi X \& baby boomer. Generasi milenial ini ingin memiliki kontrol yang kuat, keinginan untuk menyukai pekerjaannya, memiliki potensi di masa depan dan lingkungan kerja yang kekeluargaan (Bryne, 2005). Dalam hal pekerjaan, millenial juga menginginkan perusahaan yang mempunyai sistem yang dapat mengembangkan diri mereka dan proses coaching yang jelas dari atasan (Jalal, 2013). Gilbert (Gilbert, 2011) mengatakan bahwa millenial juga menyukai tantangan dan keseimbangan kerja / work life balance dalam bekerja. Hasil Survei Delloitte Consulting LLP (LLP, 2009) menunjukkan bahwa 48,9 \% karyawan millenial yang tidak puas dengan pekerjaannya berencana untuk keluar setelah enam bulan hingga dua tahun bekerja. 
Bothma (2011, dalam (Bothma \& Roodt, 2013) menyatakan bahwa fenomena turn over dapat memberikan pengaruh yang signifikan terhadap biaya perekrutan dan training karyawan dalam organisasi. Menurut Rokhman dan Riani (Rokhmah \& Riani, 2005), bagi karyawan keinginan untuk meninggalkan organisasi (turn over intention) merupakan salah satu jalan keluar untuk mendapatkan keadaan yang lebih baik. Bester (2012, dalam (Bothma \& Roodt, 2013) memandang bahwa turn over intention sebagai tahap akhir dalam pembuatan keputusan sebelum seseorang keluar dari tempatnya bekerja, pertimbangan untuk memikirkan alternatif pekerjaan lain muncul ketika karyawan mempersepsikan bahwa tidak adanya keseimbangan waktu dalam hidup dan kerja (Posig \& Kickul, 2004). Szostak (1998, dalam (Fonseca \& Verma, 2001) menyatakan bahwa ketidakseimbangan antara kerja dan keluarga akan menuntut pada berkurangnya performa kerja, meningkatnya tingkat absen, tingginya turn over, moral yang buruk, meningkatnya konflik dan tingginya ketidakadilan terhadap kapasitas kerja. Preeti Singh \& Parul Khanna (Preeti \& Parul, 2011) menyatakan work life balance adalah konsep luas yang melibatkan penetapan prioritas yang tepat antara pekerjaan (karir dan ambisi) dan kehidupan (kebahagiaan, waktu luang, keluarga dan pengembangan spiritual). Menurut Kaiser et al (2010; dalam (Živčicová, Bulková, \& Masárová, 2017), work life balance menjadi salah satu faktor yang mempengaruhi komitmen berorganisasi pada karyawan. Di sisi lain, Dale Carneige Training (Dale Carnegie \& Associate, 2016), menyatakan bahwa employee engagement didefinisikan sebagai komitmen karyawan secara emosional dan intelektual untuk berkontribusi terhadap pekerjaan. Menurut Schaufeli, et al (Schaufeli, Salanova, Gonzales, \& Bakker, 2002), engagement didefinisikan sebagai suatu sikap pandang positif yang berhubungan dengan pekerjaan dengan karakteristik dari semangat (vigor), dedikasi (dedication), dan absorpsi (absorption). Kahn (Kahn, 1990) menggambarkan bahwa keterikatan terbentuk di saat karyawan merasa saling terkait secara fisik, koginitif, dan emosional terhadap pekerjaannya.

Berdasarkan fenomena di atas peneliti tertarik untuk menganilisis lebih lanjut sejauh mana employee engagement dapat dan work life balance dapat berpengaruh pada turn over intention di generasi millenial Jakarta. Dengan demikian, tujuan dalam penelitian ini adalah: 1) untuk mengetahui pengaruh negatif dan signifikan dari employee engagement terhadap turn over intention di generasi millenial, 2) untuk mengetahui pegaruh negatif dari work life balance terhadap turn over intention di generasi millenial Jakarta.

\section{METODE}

\section{Jenis Penelitian}

Jenis penelitian yang digunakan adalah penelitian kuantitatif non experimental, dimana tidak adanya manipulasi yang dilakukan terhadap objek. Rancangan penelitian yang digunakan dalam penelitian ini adalah metode deskriptif, dimana penelitian mencoba untuk mendeskripsikan sebuah fenomena, kejadian atau situasi (Christensen; dalam (Seniati, 2008)

\section{Gambaran Populasi dan Sampel}

Populasi data yang digunakan dalam penelitian ini adalah generasi millenial yang bekerja di di perusahaan yang berlokasi di DKI Jakarta. Sampel adalah bagian dari jumlah dan karakteristik yang dimiliki oleh populasi (Sugiyono, 2011). Karakteristik sampel yang akan digunakan dalam penelitian ini, adalah: 1) Generasi millenial yang berusia 20-36tahun, 2) Bekerja di Jakarta, 3) Berjenis Kelamin Pria atau Wanita. Ukuran sampel dalam penelitian ini mengacu pada pendapat Sugiyono (2011) yang menyatakan bahwa penelitian multivariate (termasuk analisis regresi berganda), sebaiknya ukuran sampel yang digunakan adalah 10x lebih besar dari jumlah variabel dalam penelitian dan berjumlah antara 30 sampai dengan 500 . Dalam penelitian ini terdapat 3 variabel yang terdiri dari variabel bebas dan terikat. Oleh karena itu, didasarkan pada Sugiyono (2011), sampel penelitian ini adalah 31 responden millenial yang bekerja di wilayah Jakarta. 


\section{Jenis dan Sumber Data}

Data yang digunakan di dalam penelitian ini adalah data primer. Data primer adalah data yang dikumpulkan dan diolah secara perorangan dan diperoleh langsung dari sumber obyeknya. Teknik pengumpulan data yang digunakan dalam penelitian ini adalah kuesioner langsung. Kuesioner adalah sekumpulan pertanyaan yang dibuat secara tertulis yang digunakan untuk memperoleh informasi dari responden dalam arti laporan tentang pribadinya, atau halhal yang diketahui (Arikunto, 2002). Skala yang digunakan dalam penelitian ni adalah skala Likert yaitu skala yang memiliki lima kategori jawaban $(1-5)$ yang bertujuan untuk menunjukkan respon terhadap terhadap pertanyaan-pertanyaan di dalam kuesioner (Malhotra, 2010).

\section{Teknik Analisis Data}

Teknik analisis data yang digunakan dalam penelitian ini menggunakan program statistika dengan nama Statistical Product and Service Solutions (SPSS ver.23). Pengujian yang dilakukan dalam penelitian, terdiri dari : 1) Uji Validitas, untuk menunjukkan seberapa baik suatu instrumen yang digunakan untuk mengukur konsep tertentu yang ingin diukur (Sekaran, 2006), 2) Uji Reabilitas, yang digunakan di dalam penelitian ini akan menggunakan metode Cronbach Alpha, dimana semakin besar Alpha Cronbach maka akan semakin besar keandalan alat ukurnya, 3) Uji Normalitas, dilakukan untuk melihat apakah data terdistribusi secara normal atau tidak dengan melihat pancaran titik-titik pada garis yang dihasilkan melalui SPSS (Q-Q Plot), 4) Uji Regresi Berganda, dengan bantuan dari Uji pengaruh simultan (F) dan Uji Partial (Uji t).

\section{HASIL \& BAHASAN}

\section{Uji Validitas}

Validitas adalah ketepatan atau kecermatan suatu instrument dalam mengukur apa yang ingin diukur. Uji validitas digunakan untuk mengukur sah atau valid tidaknya suatu kuesioner. Suatu kuesioner dikatakan valid jika pertanyaan pada kuesioner mampu untuk mengungkap sesuatu yang akan diukur oleh kuesioner tersebut. (Ghozali, 2011). Uji validitas dilakukan dengan tingkat signifikansi sebesar 5\% dan diuji pada 31 responden (diperoleh $\mathrm{df}=29$ ) dan rtabel sebesar 0,3550 . Nilai akan dinyatakan valid apabila nilai hitung $r$-hitung $>r$-tabel. Berikut hasil perhitungan validitas data: $r_{\text {hitung }}>r_{\text {tabel }}$ dinyatakan valid.

\section{Tabel 1}

Hasil Uji Validitas Item

\begin{tabular}{|l|l|l|l|l|}
\hline Variabel & Item & r hitung & r tabel & Keputusan \\
\hline Employee Engagement $(\mathrm{X} 1)$ & Item 1 & 0,757 & 0,3550 & Valid \\
\hline & Item 2 & 0,875 & 0,3550 & Valid \\
\hline & Item 3 & 0,771 & 0,3550 & Valid \\
\hline & Item 4 & 0,672 & 0,3550 & Valid \\
\hline & Item 5 & 0,642 & 0,3550 & Valid \\
\hline & Item 6 & 0,667 & 0,3550 & Valid \\
\hline & Item 7 & 0,802 & 0,3550 & Valid \\
\hline & Item 8 & 0,893 & 0,3550 & Valid \\
\hline & Item 9 & 0,850 & 0,3550 & Valid \\
\hline & Item 10 & 0,779 & 0,3550 & Valid \\
\hline & Item 11 & 0,827 & 0,3550 & Valid \\
\hline & Item 12 & 0,783 & 0,3550 & Valid \\
\hline & Item 13 & 0,814 & 0,3550 & Valid \\
\hline & Item 14 & 0,736 & 0,3550 & Valid \\
\hline & Item 15 & 0,591 & 0,3550 & Valid \\
\hline Work Life Balance (X2) & Item 16 & 0,485 & 0,3550 & Valid \\
\hline & Item 1 & 0,820 & 0,3550 & Valid \\
\hline & Item 2 & 0,850 & 0,3550 & Valid \\
\hline & Item 3 & 0,909 & 0,3550 & Valid \\
\hline & Item 4 & 0,877 & 0,3550 & Valid \\
\hline Turn Over Intention (Y) & Item 5 & 0,664 & 0,3550 & Valid \\
\hline & Item 1 & 0,748 & 0,3550 & Valid \\
\hline
\end{tabular}




\begin{tabular}{|l|l|l|l|l|}
\hline & Item 2 & 0,684 & 0,3550 & Valid \\
\hline & Item 3 & 0,896 & 0,3550 & Valid \\
\hline & Item 4 & 0,725 & 0,3550 & Valid \\
\hline
\end{tabular}

Sumber: Data diolah, 2017

Dari hasil pengujian data menggunakan SPSS V23, dapat disimpulkan bahwa pada seluruh item kuesioner dinyatakan valid, dikarenakan pada Corrected Item-Total Correlation nilai $r$-hitung $>\mathrm{r}$ tabel.

\section{Uji Reabilitas}

Dalam perhitungan menggunakan SPSS, data dinyatakan reliabel jika pada kolom Cronbach's Alpha $>=0,6$. Cronbach Alpha merupakan sebuah ukuran keandalan yang memiliki nilai berkisar dari nol sampai satu. Menurut Priyatno (Priyatno, 2010), reliabilitas kurang dari 0,6 adalah kurang baik, sedangkan 0,7 dapat diterima dan di atas 0,8 dinyatakan baik. Berikut merupakan hasil uji reliabilitas variabel employee engagement, work life balance dan turn over intention:

Tabel 2

Hasil Uji Reliabilitas Item

\begin{tabular}{|c|c|c|}
\hline Variabel & Alpha Cronbach & Keputusan \\
\hline Employee Engagement $(\mathrm{X} 1)$ & 0,945 & Reliabel Baik \\
\hline Work Life Balance $(\mathrm{X} 2)$ & 0,881 & Reliabel diterima \\
\hline Turn Over Intention $(\mathrm{Y})$ & 0,761 & Reliabel diterima \\
\hline
\end{tabular}

Sumber: Data diolah, 2017

Dari tabel di atas, dapat diketahui bahwa nilai Cronbach Alpha untuk ketiga variabel berada pada poisisi di atas 0,7. Berdasarkan nilai di atas, disimpulkan bahwa alat ukur kuesioner yang digunakan reliabel atau telah memenuhi syarat reliabilitas.

\section{Uji Normalitas}

Uji ini bertujuan untuk menguji apakah dalam model regresi, variabel terikat dan variabel bebas, keduanya mempunyai distribusi normal. Dasar pengambilan keputusannya sebagai berikut:

a. Jika data menyebar disekitar garis diagonal dan mengikuti arah garis diagonalnya, maka model regresi memenuhi asumsi normalitas.

b. Jika data menyebar jauh dari garis diagonal dan tidak mengikuti arah garis diagonal, maka model regresi tidak memenuhi asumsi normalitas.

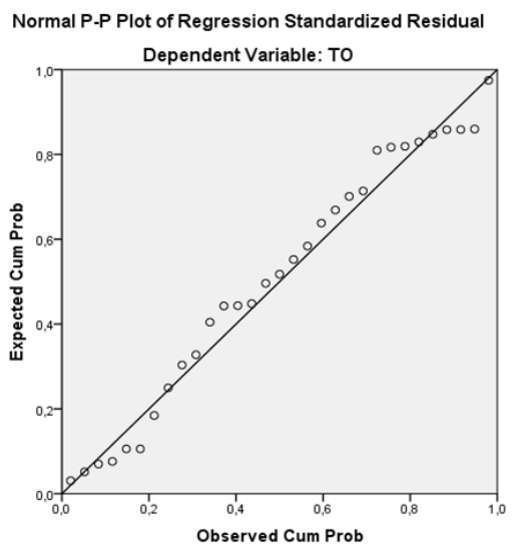

Gambar 1

\section{Normal P-Plot of Regression Standarized Residual}

Sumber: Data diolah oleh SPSS v.23

Dari hasil uji normalitas di atas, diketahui bahwa data berada di sekitar garis diagonal dan mengikuti arah garis diagonalnya, maka model regresi memenuhi asumsi normalitas.

\section{Uji Regresi Berganda}

Analisis regresi linier berganda digunakan untuk mengetahui pengaruh variabel independen terhadap variabel dependen baik secara parsial (uji t) maupun secara bersama-sama (uji F). 
Tabel 3

Analisis Regresi

\begin{tabular}{|c|c|c|c|}
\hline Model & B & t & Sig. \\
\hline (Constant) & 2,583 & 2,387 &, 024 \\
\hline EE (X1) &,- 266 & $-1,162$ &, 255 \\
\hline WLB (X2) &, 444 & 2,534 &, 017 \\
\hline
\end{tabular}

Sumber: Data diolah oleh SPSS v.23

Berdasarkan tabel di atas, ditemukan persamaan regresi sebagai berikut :

$$
Y=2,853-0,266 \times 1+0,444 X 2
$$

Pernyataan yang dihasilkan adalah koefisien regresi X1 sebesar - 0,266, EE(X1) mengalami kenaikan 1\%, maka $\mathrm{TO}(\mathrm{Y})$ akan mengalami penurunan sebesar 26,6\%. Dapat dikatakan bahwa terjadinya hubungan negatif antara $\mathrm{EE}(\mathrm{X} 1)$ \& $\mathrm{TO}(\mathrm{Y})$. Koefisien regresi X2 sebesar 0,444, WLB(X2) mengalami kenaikan 1\%, maka TO(Y) akan mengalami kenaikan 44,4\%. Terjadinya hubungan positif antara WLB (X2) dan TO (Y).

Uji t yang dilakukan adalah dengan menggunakan perhitungan $\mathrm{df}=\mathrm{n}-\mathrm{k}-1$ atau $31-2-1=$ 28 dan signifikansi 0,05, dengan demikian nilai t-tabel yang digunakan sebesar 1,701/-1,701. Dasar pengambilan keputusan, yaitu:

a. Jika t-hitung $<=\mathrm{t}$-tabel atau probabilitas $>=0,05$ maka Ho diterima

b. Jika t-hitung $>$ t-tabel atau probabilitas $<0,05$ maka Ho ditolak

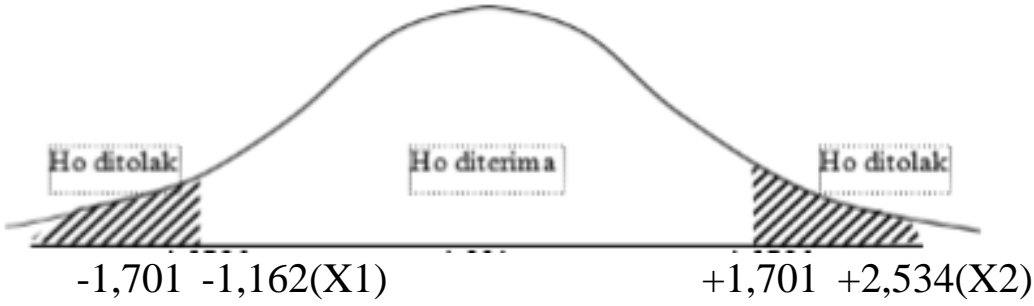

Gambar 2

Daerah penentuan Ho

Berdasarkan tabel 3 ditunjukkan bahwa nilai t-hitung dari EE(X1) sebesar -1,162, ditemukan bahwa t-hitung $<\mathrm{t}$-tabel $(-1,162<1,701)$, maka Ho diterima, artinya bahwa employee engagement secara parsial berpengaruh terhadap turn over intention. Nilai t negatif, artinya bahwa setiap kenaikan variabel employee engagement mempunyai hubungan yang berlawanan arah setiap kenaikan satu satuan maka akan menurunkan turn over intention. Dengan kata lain, apabila karyawan memiliki engagement dengan perusahaan, maka akan semakin cenderung bertahan dalam perusahaan dan tidak memiliki keinginan untuk berpindah atau keluar dari perusahaan. Hal ini juga didukung oleh hasil penelitian sebelumnya yang dilakukan oleh Lamidi (2010, dalam (Widjaja, Kristanti, \& Purnamasari, 2015) mengemukakan bahwa employee engagement dapat menurunkan kecenderungan untuk berpindah pekerjaan. Penelitian lainnya yang dilakukan oleh Park \& Gursoy (2012, dalam (Widjaja, Kristanti, \& Purnamasari, 2015) menyatakan bahwa ketiga dimensi employee engagement (vigor, dedication, dan absorption) memiliki pengaruh yang negatif terhadap turn over intention.

Nilai t-hitung WLB(X2) sebesar +2,534, ditemukan bahwa t-hitung > t-tabel $(+2,534>1,701)$, maka Ho ditolak, artinya bahwa work life balance secara parsial berpengaruh terhadap turn over intention. Nilai t-hitung positif, artinya bahwa semakin meningkatnya work life balance akan meningkatkan turn over intention. Dengan kata lain, ketika karyawan merasa work life balance yang tinggi, maka akan semakin tinggi tingkat turn over intention. Hal ini didukung pula oleh Szostak (1998, dalam (Fonseca \& Verma, 2001) menyatakan bahwa ketidakseimbangan antara kerja dan keluarga akan menuntut pada berkurangnya performa kerja, meningkatnya tingkat absen, tingginya turnover, moral yang buruk, meningkatnya konflik dan tingginya ketidakadilan terhadap kapasitas kerja.

Uji $\mathrm{F}$, digunakan untuk mengetahui apakah variabel independen secara simultan berpengaruh terhadap variabel dependen atau tidak. 
Tabel 4

Uji F (Anova)

ANOVA ${ }^{\mathrm{a}}$

\begin{tabular}{|ll|r|r|r|r|r|}
\hline Model & & Sum of Squares & df & Mean Square & F & Sig. \\
\hline 1 & Regression & 11,144 & 2 & 5,572 & 8,166 &, $002^{\mathrm{b}}$ \\
& Residual & 19,106 & 28 &, 682 & & \\
& Total & 30,250 & 30 & & & \\
\hline
\end{tabular}

a. Dependent Variable: TO

b. Predictors: (Constant), WLB, EE

Berdasarkan tabel 1.4, diperoleh F-hitung sebesar 8,166, dengan menggunakan tingkat signifikansi 0,05, df1 (k-1 atau 2-1) = 1 dan df2(n-k-1 atau 31-2-1) = 29, F-tabel yang digunakan sebesar 4,182964 atau 4,183. Karena F-hitung > F-tabel $(8,166>4,183)$, maka dinyatakan bahwa seluruh variabel employee engagement dan work life balance bersama-sama berpengaruh terhadap turn over intention.

\section{KESIMPULAN DAN SARAN Kesimpulan}

Berdasarkan analisa dan pembahasan, dapat disimpulkan sebagai berikut:

1. Penelitian ini menyebarkan kuesioner kepada 31 responden generasi millenial yang bekerja di wilayah Jakarta, dengan kategori 17 pria dan 14 wanita. Range usia didominasi oleh usia 26-30 tahun dan wilayah tempat bekerja di area Jakarta Barat.

2. Hipotesis 1: terbukti bahwa variabel employee engagement berpengaruh negatif terhadap turn over intention di generasi millenial Jakarta.

3. Hipotesis 2: tidak terbukti bahwa variabel work life balance berpengaruh negatif terhadap

\section{Saran} turn over intention di generasi millenial Jakarta.

1. Diharapkan agar perusahaan-perusahaan di Jakarta dapat semakin meningkatkan employee engagement di lingkungan kerjanya, hal tersebut dapat dilakukan dengan melakukan kegiatan yang bertujuan untuk mempererat hubungan antar karyawan dan perusahaan, seperti melakukan gathering bersama, dengan demikian karyawan dapat semakin mempererat hubungan antar rekan kerja ataupun perusahaan dan dapat menimbulkan semangat kerja. Di lain hal, perusahaan di Jakarta, melalui divisi Human Resource dapat merangkul para generasi millenial ini, melalui konseling ataupun tes kemampuan, hal ini bertujuan untuk selalu mengeksplor kemampuan dari karyawan sendiri. Dengan demikian, karyawan generasi millenial ini dapat semakin terlibat dan berperan serta dalam kemajuan dari perusahaan.

2. Untuk penelitian selanjutnya, peneliti dapat melakukan pesebaran data lebih banyak, sehingga dapat diperoleh data yang normal dan dapat dianalisis lebih lanjut. Pesebaran data dapat lebih mewakili generasi millenial yang bekerja di Jakarta. Dengan demikian dapat lebih mengetahui hubungan antar variabel-variabel.

3. Aspek-aspek dimensi dari tiap variabel dapat lebih dikaitkan dengan subyek penelitian yang berperan serta.

4. Penelitian selanjutnya, dapat menggunakan responden baby boomers ataupun generasi $\mathrm{X}$ sebagai populasi penelitian. Penyebarannya pun dapat dilakukan di luar Jakarta, sehingga dapat diperoleh gambaran merata terkait hubungan dari employee engagement, work life balance dan turn over intention.

\section{DAFTAR REFERENSI}

Arikunto, S. (2002). Prosedur Penelitian Suatu Pendekatan Praktek. Jakarta: Asdi Mahastya. Bothma, C. F., \& Roodt, G. (2013). The validation of the turnover intention scale. SA Journal of Human Resources Management/SA Tydskrif vir Menslikehulpbronsbestuur, 11(1), 12 pages. 
Bryne, U. (2005). Work-life balance: Why are we talking about it at all? Business Information Review.

Carnegie, D. \& Associate. (2016). Igniting Millenial Engagement. Jakarta: Dale Carnegie Training White Paper.

Fonseca, M., \& Verma, A. (2001). Learning and work life balance in Canada: evidence from the general social survey. CIRA XXXVIII Annual Conference in Quebec City. Quebec City.

Ghozali, I. (2011). Aplikasi Analisis Myultivariate dengan Program IBM SPSS 19 (5 ${ }^{\text {th }}$ ed.). Semarang: Universitas Diponegoro.

Gilbert, J. (2011). The Millenials: A new generation of employees, a new set of engagement policies. Ivey Business Journal .

Hillman, D. R. (2014). Understanding multigenerational work-value conflict resolution. Journal of Workplace Behavioral Health.

Jalal, O. M. (2013). Mengenal Siapa itu Generasi Y. PPM Manajemen.

Kahn, W. A. (1990). Psychological conditions of personal engagement \& disengagement at work. Academy of Management Journal, 33(4), 692-724.

LLP, D. C. (2009). Generation Y: Powerhouse of The Global Economy. UK: Deloitte Development LCC.

Malhotra, N. (2010). Markteting Research: An Applied Orientation. New Jersey: Pearson Education.

Posig, M., \& Kickul, J. (2004). Work role expectations and work family conflict: gender differences in emotional exhaustion. Women in Management Review, 19(7), 373-386.

Prameswari, V., \& Respati, A. (2014). Perbedaan work values antara generasi x dan generasi y. Jurnal Psikologi Universitas Indonesia.

Preeti, S., \& Parul, K. (2011). Work-Life Balance-A Tool for increased Employee Productivity and Retention.

Priyatno, D. (2010). Cara Mudah dan Cepat Melakukan Analisis Data Penelitian. Yogyakarta: Gava Media.

Rokhmah, B. E., \& Riani, A. L. (2005). Keterkaitan antara komitmen afektif dengan intensi turnover pada karyawan bagian produksi di PT. Usman Jaya Mekar Magelang. Jurnal Ilmiah Teknik Industri, 4(2), 78-85.

Santoso, S. (2017). Menguasai Statistik dengan SPSS 24. Jakarta: Gramedia.

Schaufeli, W. B., Salanova, M., Gonzales, R. V., \& Bakker, A. B. (2002). The measurement of engagement: a confirmative analytic approach. Journal of Happiness Studies, 3, 7192.

Sekaran, U. (2006). Metodologi Penelitian untuk Bisnis (4 ${ }^{\text {th }}$ ed., vol. 1). Jakarta: Salemba Empat.

Seniati, d. (2008). Psikologi Eksperimen. Jakarta: Indeks.

Sugiyono. (2011). Metode Penelitian Kuantitatif Kualitatif dan R\&D. Bandung: Alfabeta.

Suhaimi, S. (2016). Jakarta dalam Angka. Retrieved from Badan Pusat Statistik Provinsi DKI Jakarta: http://jakarta.bps.go.id/backend/pdf_publikasi/Jakarta-Dalam-Angka-2016.pdf

Widjaja, D. C., Kristanti, S. E., \& Purnamasari, M. (2015). Pengaruh employee engagement terhadap kepuasan kerja dan turn over intention di Swiss Belinn Surabaya. Jurnal Hospitality dan Manajemen Jasa, 3(1).

Živčicová, E., Bulková, K., \& Masárová, T. (2017). Comparison of the selected indicators of work life balance in European Union countries. Economics and Sociology, 10(1), 222231. 